Archives

$7 \mid 1991$

Varia

\title{
France et Europe centrale : les intermédiaires
}

\section{Krysztof Pomian}

\section{(2) OpenEdition}

\section{Journals}

Édition électronique

URL : http://journals.openedition.org/ccrh/2840

DOI : $10.4000 /$ ccrh. 2840

ISSN : $1760-7906$

Éditeur

Centre de recherches historiques - EHESS

Édition imprimée

Date de publication : 15 avril 1991

ISSN : 0990-9141

Référence électronique

Krysztof Pomian, «France et Europe centrale : les intermédiaires », Les Cahiers du Centre de

Recherches Historiques [En ligne], 7| 1991, mis en ligne le 18 mars 2009, consulté le 02 mai 2019.

URL : http://journals.openedition.org/ccrh/2840 ; DOI : 10.4000/ccrh.2840

Ce document a été généré automatiquement le 2 mai 2019.

Article L.111-1 du Code de la propriété intellectuelle. 


\title{
France et Europe centrale : les intermédiaires
}

\author{
Krysztof Pomian
}

1 L'Europe centrale et orientale est composée de dix-sept pays ${ }^{1}$. Le nombre de nations et de langues y dépasse la trentaine et, à côté des quatre grandes confessions chrétiennes - sans même parler des sectes - la religion juive et l'Islam y sont également représentés depuis des siècles. Autant dire qu'on peut être historien de la Bohême ou du Monténégro mais pas de l'Europe centrale et orientale, même si on laisse de côté la Russie qui en fait pourtant partie, tout en étant un monde en soi.

2 D'où une question tout à fait pratique et terre-à-terre: peut-on trouver un objet de recherche commun aux historiens qui étudient, chacun, un autre pays de l'Europe centrale ou orientale et qui, de surcroit, s'intéressent, dans les pays qu'ils étudient, à des domaines fort éloignés, pour certains, les uns des autres? A cette question, la création du séminaire sur «L'histoire comparée des sociétés européennes: l'Europe centrale et l'Europe de l'Ouest ", nous a obligé à donner une réponse. Celle-ci ne pouvait être que pragmatique : au cours des trois années d'existence du séminaire des sujets très variés ont été abordés, ayant trait à l'histoire des pays de l'Europe centrale et orientale ou de ces régions prises dans leur ensemble. Mais petit à petit, les participants se sont accordés sur le fait que l'objet que chacun a eu à étudier - fut-ce marginalement - dans le cadre de ses recherches et qui, à ce titre, se prête bien à fournir au séminaire un commun dénominateur, est constitué par les intermédiaires culturels entre la France et les pays de l'Europe centrale et orientale: les voyageurs, les cartographes et les géographes, les diplomates, les écrivains, publicistes, théoriciens du droit et de la politique, les spécialistes français de ces régions, les émigrés qui en sont originaires, les traducteurs, etc.

3 Une recherche de ce type ne montre toutefois son plein intérêt que si elle est faite dans une perspective plus large : celle d'une histoire de la découverte par les Français de la partie de l'Europe à laquelle nous donnons - depuis quand? - les noms de «Europe centrale » et/ou de "Europe de l'Est», et de l'intégration de son existence et de sa spécificité dans leur vision du continent et de ses problèmes. Cela commence certes dès le 
Moyen-Age, mais cela s'intensifie à partir du XVIII ${ }^{e}$ siècle et surtout après la Révolution, en fonction des événements qui se produisent en Europe centrale et orientale même, mais aussi en fonction des changements qui affectent les rapports entre la France et l'Allemagne, la France et l'Autriche, la France et la Russie, la France et la Turquie.

Les intérêts français pour l'Europe centrale et orientale sont déterminés en effet, pour une part importante, par des considérations politiques et stratégiques. Mais le savoir qu'on acquiert sur cette région et les contacts qu'on établit avec ses ressortissants, exercent une influence sur la manière dont on conçoit les objectifs de la politique française. Il serait particulièrement instructif à cet égard, d'étudier l'histoire des idées que l'on se faisait en France, entre 1871 et 1918, sur les différents pays de l'Europe centrale et orientale, les hommes qui en étaient les auteurs et les propagateurs, les groupes de pression qui s'efforçaient d'imposer à la politique de la France telle ou telle autre orientation, le rôle des facteurs militaires, économiques, culturels, mais aussi des ignorances et des préjugés.

On voit qu'une telle perspective permet d'étudier l'assimilation par la culture et la politique françaises, c'est-à-dire par des Français qu'il faut situer dans le temps, l'espace et la hiérarchie sociale, de l'existence des nations Centre-Est-européennes avec leurs histoires et leurs cultures. Qu'elle permet, autrement dit, d'étudier un aspect important de l'intégration mentale de la France à l'Europe. Et qu'elle permet, à ce titre, de mettre en relation avec les grands problèmes de l'histoire de France de nombreux travaux ponctuels qui, isolés les uns des autres, peuvent sembler ne relever que de l'érudition pure.

Les articles réunis dans le présent numéro des Cahiers $d u C R H$ ont pour trait commun d'avoir été présentés dans le séminaire sur "L'histoire comparée des sociétés européennes». Ils illustrent, pour trois d'entre eux, les voies différentes de l'établissement des liens avec les pays de l'Europe centrale et orientale, de la constitution d'un savoir sur ceux-ci et de son fonctionnement dans la culture française. Le quatrième traite d'un thème central de l'histoire de ces régions dont une des particularités historiques fut, pendant des siècles, une forte densité de la population juive.

\section{NOTES}

1. Voir K. POMIAN, «Les particularités historiques de l'Europe centrale et orientale », Le Débat, $\mathrm{n}$

o 63, janvier-février 1991, pp. 26-39. 


\section{AUTEUR}

\section{KRYSZTOF POMIAN}

Krzysztof POMIAN est directeur de recherche au CNRS et membre du Centre de Recherches Historiques. 